\title{
Hearing loss in the royal Norwegian navy: a cross-sectional study
}

\author{
Kaja Irgens-Hansen · Erlend Sunde · Magne Bråtveit • \\ Valborg Baste · Gunnhild Oftedal · Vilhelm Koefoed · \\ Ola Lind · Bente Elisabeth Moen
}

Received: 10 February 2014 / Accepted: 22 September 2014 / Published online: 7 October 2014

(C) The Author(s) 2014. This article is published with open access at Springerlink.com

\begin{abstract}
Objectives Prior studies have indicated a high prevalence of noise-induced hearing loss (NIHL) among Navy personnel; however, it is not clear whether this is caused by work on board. The present study aimed to assess the prevalence of hearing loss among Navy personnel in the Royal Norwegian Navy (RNoN), and to investigate whether there is an association between work on board RNoN vessels and occurrence of hearing loss.

Methods Navy personnel currently working on board $\mathrm{RNoN}$ vessels were recruited to complete a questionnaire on noise exposure and health followed by pure tone audiometry. Hearing loss was defined as hearing threshold levels $\geq 25 \mathrm{~dB}$ in either ear at the frequencies $3,000,4,000$ or $6,000 \mathrm{~Hz}$. Hearing thresholds were adjusted for age and gender using ISO 7029.

Results The prevalence of hearing loss among Navy personnel was $31.4 \%$. The work exposure variables: years of work in the Navy, years on vessel(s) in the Navy and years of sailing in the Navy were associated with reduced hearing
\end{abstract}

\footnotetext{
K. Irgens-Hansen $(\bowtie) \cdot$ E. Sunde $\cdot$ M. Bråtveit $\cdot$ V. Baste $\cdot$

B. E. Moen

Department of Global Public Health and Primary Care, Research Group for Occupational and Environmental Medicine, University of Bergen, Årstadveien 21, 5009 Bergen, Norway

e-mail: kaja.irgens@igs.uib.no

E. Sunde

e-mail: erlend.sunde@igs.uib.no

M. Bråtveit

e-mail: magne.bratveit@igs.uib.no

V. Baste

e-mail: valborg.baste@igs.uib.no

B. E. Moen

e-mail: bente.moen@cih.uib.no
}

after adjusting for age, gender and otitis as an adult. Among the work exposure variables, years of sailing in the Navy was the strongest predictor of reduced hearing, and significantly reduced hearing was found at the frequencies 1,000 , 3,000 and 4,000 $\mathrm{Hz}$.

Conclusions Our results indicate that time spent on board vessels in the $\mathrm{RNoN}$ is a predictor of reduced hearing.

Keywords Audiometry $\cdot$ Hearing conservation $\cdot$ Hearing loss $\cdot$ Noise exposure $\cdot$ Noise-induced hearing loss

\section{Introduction}

Noise-induced hearing loss (NIHL) is considered to be one of the most prevalent work-related diseases worldwide. A worldwide analysis states that $16 \%$ of disabling hearing loss in adults is attributable to occupational noise exposure (Nelson et al. 2005).

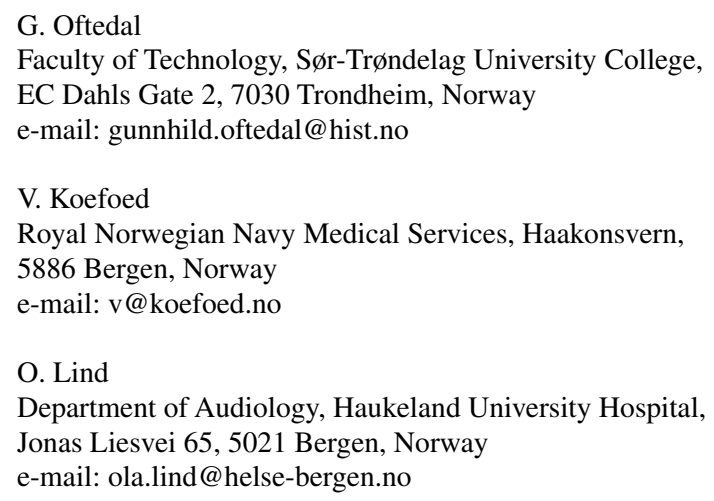


Studies on occurrence of hearing loss among Navy personnel are infrequent, and to our knowledge, no studies have been published recently (Trost and Shaw 2007; Wolgemuth et al. 1995). Previous studies from the USA have reported noise exposure to be the most prevalent occupational health hazard in the US Navy (Bohnker et al. 2002b), and deteriorated hearing thresholds have been found among $29 \%$ of Navy personnel (Wolgemuth et al. 1995).

Prior studies on hearing loss among Navy personnel have primarily been based on data collected with the purpose of describing and monitoring effects of hearing conservation programs, and hearing has not always been examined systematically in these studies. Few studies have included strict protocol-based measurements, and they have not always considered other potential causes of hearing loss, as for instance non-occupational noise exposure, prior ear disease or exposure to ototoxic medication. The relationship between hearing loss and work on the vessels has not been clearly documented in prior studies.

Navy operations at sea cause noise levels on board RNoN vessels that are higher than recommended limit values (Irgens-Hansen et al. 2013; Koefoed 2011), and in a RNoN study on health and work environment, self-reported prevalence of reduced hearing was $24 \%$ (Moen et al. 2008)

The aim of this study was to assess the prevalence of hearing loss and examine the association between work on board vessels in the RNoN and hearing loss among Navy personnel.

\section{Methods}

\section{Study population}

From April 2012 to June 2013, Navy personnel currently working on board RNoN vessels were asked to participate in a cross-sectional study on noise and hearing by completing an audiometric test and a questionnaire on noise exposure and health. The Navy personnel recruited included officers, enlisted personnel and civilians; $99 \%$ were Caucasians. The total number of Navy personnel fluctuates, and a complete list was not possible to obtain; however, 938 (of the approximately 948 Navy personnel counted at the beginning of the project period) were asked to take part. Information about the study was given in plenary by the management on board each vessel and was also provided through a written letter handed out prior to examination. The study was carried out by trained personnel at the two naval bases (Bergen and Sortland), supervised by a researcher from the University of Bergen. A total of 581 participants were examined in Bergen, while 191 were examined in Sortland.

\section{Questionnaire}

The questionnaire comprised questions regarding occupational and non-occupational factors which could possibly induce hearing loss (Table 1). This included questions about work history, current and prior noise exposure at work and during leisure time, use of hearing protection, general and ear-related medical history, use of ototoxic medication, diving, exposure to ototoxic chemicals, smoking and use of moist snuff. The completed questionnaires were assessed by the personnel who examined the hearing, and participants were asked to clarify ambiguous or missing answers.

\section{Pure tone audiometry}

A stepwise test protocol was developed in cooperation with an otolaryngologist and was followed by the personnel performing the audiometry. A checklist was used to ensure that all steps in the procedure were followed. Otological examination was performed prior to audiometry. In cases of complete ear canal obstructions, cerumen was removed and a new appointment was made at least one week later. Pure tone audiometry was done using Interacoustics AD226 with Amplivox Audiocups or Peltor earphones with a lower test limit of $-10 \mathrm{~dB}$, or with Welch Allyn GSI with TDH $39 \mathrm{P}$ earphones with a lower test limit of $+10 \mathrm{~dB}$. Background noise in the two booths used was measured (15 s) with Brüel \& Kjaer sound level meter Hand-held Analyzer Type 2250. The background noise was in accordance with ISO 8253-1 (2010) for all frequencies (in the range 31.5$8,000 \mathrm{~Hz})$ with the highest $\mathrm{L}_{\max }$ at $55 \mathrm{~dB}(31.5 \mathrm{~Hz})$. The frequencies selected for audiometry were the following: 250, 500, 1,000, 2,000, 3,000, 4,000, 6,000 and 8,000 Hz. The equipment was calibrated prior to audiometry (ISO 8253-1 2010).

An automated procedure was used, but if there was uncertainty regarding measured hearing thresholds, ongoing tinnitus or former recognized hearing loss, manual audiometry was performed. Individual noise exposure within the last $16 \mathrm{~h}$ prior to audiometry was evaluated by a checklist that contained the following choice of statements regarding recent noise exposure: "No loud noise exposure," "Loud area noise exposure," "Loud workshop noise exposure" and "Other loud noise exposure." Navy personnel who reported being highly exposed to noise the previous $16 \mathrm{~h}$ (who had stayed in loud area noise; e.g. engine room or workshop) and who had a hearing threshold $\geq 25 \mathrm{~dB}$ in either ear at $3,000,4,000$ or $6,000 \mathrm{~Hz}$ were excluded. In order to be included in the study, a new audiometry had to be conducted when they had not been exposed to loud noise the previous $16 \mathrm{~h}$. Audiometry was not performed in cases of present acute airway infections with additional sinus, 
Table 1 Questions and response alternatives in a questionnaire about noise exposure and health given to Navy personnel in Norway, 2012-2013

\begin{tabular}{|c|c|c|c|}
\hline & Question & Response alternatives & \\
\hline \multirow[t]{4}{*}{ Work history } & Working position & Free text ${ }^{\mathrm{b}}$ & \\
\hline & Years of work in the Navy & Number of years ${ }^{\mathrm{a}}$ & \\
\hline & Years on vessel(s) in the Navy & Number of years ${ }^{\mathrm{a}}$ & \\
\hline & Years of sailing in the Navy & Number of years ${ }^{\mathrm{a}}$ & \\
\hline \multirow{4}{*}{$\begin{array}{l}\text { Current and prior } \\
\text { occupational noise } \\
\text { exposure }\end{array}$} & $\begin{array}{l}\text { Have you been exposed to impulse noise (explosions etc.) } \\
\text { in your work in the Navy without using hearing protection? }\end{array}$ & Yes/no & Number of times ${ }^{\mathrm{a}}$ \\
\hline & $\begin{array}{l}\text { Have you had temporary reduced hearing, fullness or ringing } \\
\text { in the ears after being noise-exposed during the last year? }\end{array}$ & Yes/no & Number of times ${ }^{\mathrm{a}}$ \\
\hline & $\begin{array}{l}\text { Have you used/do you use hearing protection in high noise areas } \\
\text { on board vessels in the Navy in these periods? }\end{array}$ & $\begin{array}{l}2010-2012 \\
2000-2009 \\
<2000\end{array}$ & $\begin{array}{l}\text { Yes, most of the time } \\
\text { Sometimes } \\
\text { No } \\
\text { Of no relevance }\end{array}$ \\
\hline & Do you use hearing protection while shooting? & $\begin{array}{l}\text { Yes, most of the time } \\
\text { Sometimes } \\
\text { No }\end{array}$ & \\
\hline \multirow{6}{*}{$\begin{array}{l}\text { Current and prior } \\
\text { non-occupational } \\
\text { noise exposure }\end{array}$} & Have you been hunting/are you hunting? & Yes/no & Number of seasons ${ }^{\mathrm{a}}$ \\
\hline & Do you use hearing protection while hunting? & $\begin{array}{l}\text { Yes, most of the time } \\
\text { Sometimes } \\
\text { No }\end{array}$ & \\
\hline & Number of gunshots last year (in the Navy, hunting and sports) & Number of shots ${ }^{\mathrm{a}}$ & \\
\hline & Have you played/do you play in a band? & Yes/no & Number of years ${ }^{\mathrm{a}}$ \\
\hline & How often do you attend concerts/disco etc. playing loud music? & $\begin{array}{l}\text { Weekly }^{\mathrm{c}} \\
\text { Sometimes/month }^{\mathrm{c}} \\
\text { Sometimes/year } \\
\text { Seldom/never }\end{array}$ & \\
\hline & Do you currently use Mp3 player etc. with plugs/phones? & $\begin{array}{l}>6 \mathrm{~h} / \text { week }^{\mathrm{d}} \\
3-6 \mathrm{~h} / \text { week }^{\mathrm{d}} \\
1-2 \mathrm{~h} / \text { week } \\
\text { Seldom/never }\end{array}$ & \\
\hline \multirow[t]{6}{*}{ Medical history } & Have you ever had any of these diseases? & $\begin{array}{l}\text { Heart disease } \\
\text { Hypertension } \\
\text { Diabetes, type } 2\end{array}$ & $\begin{array}{l}\text { Yes } \\
\text { No }\end{array}$ \\
\hline & Did you have otitis as a child ( $0-17$ years)? & Yes/no/I don't know & \\
\hline & Have you had otitis as an adult (from the age of 18 years)? & Yes/no/I don’t know & \\
\hline & Have you ever been hospitalized due to head injury? & Yes/no & \\
\hline & Have/had any in you closest family reduced hearing? & $\begin{array}{l}\text { Mother/father/children/ } \\
\text { siblings/none close }\end{array}$ & \\
\hline & $\begin{array}{l}\text { Have you used ototoxic medication earlier (diuretics, } \\
\text { broad spectrum antibiotics, cytotoxins)? }\end{array}$ & Yes/no/I don’t know & \\
\hline \multirow[t]{4}{*}{$\begin{array}{l}\text { Other occupational } \\
\text { or non-occupa- } \\
\text { tional exposure }\end{array}$} & Have you been diving? & $\begin{array}{l}\text { Yes, professional in the } \\
\text { Navy } \\
\text { Yes, professional outside } \\
\text { the Navy } \\
\text { Yes, leisure diving } \\
\text { No, never }\end{array}$ & \\
\hline & $\begin{array}{l}\text { Have you had ear damage following diving (being treated } \\
\text { in pressurized tank due to the ear damage)? }\end{array}$ & Yes/no & \\
\hline & $\begin{array}{l}\text { How often do you work with organic solvents (paint/washing } \\
\text { with thinner)? }\end{array}$ & $\begin{array}{l}\text { Daily } \\
\text { Weekly } \\
\text { Monthly } \\
\text { Seldom/never }\end{array}$ & \\
\hline & Have you smoked/do you smoke? & $\begin{array}{l}\text { Yes, daily } \\
\text { Sometimes } \\
\text { Earlier } \\
\text { No }\end{array}$ & \\
\hline
\end{tabular}


Table 1 continued

\begin{tabular}{ll}
\hline Question & Response alternatives \\
\hline Have you used moist snuff/do you use moist snuff? & Yes, daily \\
& Sometimes \\
& Earlier \\
& No \\
\hline
\end{tabular}

a Continuous variables were grouped by quartiles

b The alternative "working position" was grouped into seven job categories

c The alternatives "weekly" and "sometimes/month" were merged due to low numbers to the alternative " $\geq$ sometimes/month"

d The alternatives " $>6 \mathrm{~h} /$ week" and "3-6 h/week" were merged due to low numbers to the alternative " $\geq 3 \mathrm{~h} /$ week"

nose or ear affection, and testing was postponed until the participant became asymptomatic. In cases of inadequate completion of the test protocol, the results were excluded. All results were evaluated by the researcher in cooperation with an otolaryngologist, and referral to supplementary tests was made when indicated.

A total of 772 gave their consent to join the study. In spite of a test regime controlling the audiometer and earphones, an unstable wire connection on the right earphone (Amplivox Audiocups) was discovered after some weeks of testing, affecting 110 measurements conducted in Bergen. In 24 of these cases, an additional audiometry was performed by qualified personnel assigned to the project. We were not able to retrieve the remaining 86 participants for an additional audiometry. Due to this technical failure as well as to insufficient compliance with the test protocol, results from a total of 167 participants had to be excluded, leaving 605 participants included in the study (Fig. 1).

Analysis

Results are presented as descriptive statistics, using percent, mean, standard deviation (SD) and Pearson correlation coefficient $(\mathrm{R})$.

Participants were categorized into job categories according to working position on board. Hearing loss was defined as hearing threshold levels $\geq 25 \mathrm{~dB}$ in either ear at 3,000, 4,000 or $6,000 \mathrm{~Hz}$. Continuous variables of potential determinants of hearing loss were categorized in quartiles. Log binomial regression provided relative risks (RR) with $95 \%$ confidence intervals (CI) of hearing loss among the different determinants. Only determinants with significant impact on hearing were presented.

In order to adjust for the influence of age and gender on hearing, a new variable was constructed. Based on ISO 7029 (2000), we calculated the age and gender-specific hearing threshold and compared this expected value with the respective participants' measured hearing thresholds. In this calculation, the 50 percentile hearing threshold provided in the ISO standard was chosen. Deviation from the expected hearing threshold value was calculated as:
$\Delta$ Hearing threshold $=$ measured hearing threshold

- expected hearing threshold according to ISO 7029

A $\Delta$ Hearing threshold $<0$ indicated a better hearing than according to ISO $7029, \Delta$ Hearing threshold $=0$ indicated hearing equal to ISO 7029 , while $\Delta$ Hearing threshold $>0$ indicated poorer hearing than according to ISO 7029. This calculation was made for each frequency for both ears, and for each participant, the poorest $\Delta$ Hearing threshold of the two ears for each frequency was chosen.

The association between the work exposure variables (years of work in the Navy, years on vessel(s) in the Navy and years of sailing in the Navy) and $\Delta$ Hearing threshold for each frequency was analyzed by linear regression providing $\beta$ and $95 \% \mathrm{CI}$. The results were adjusted for otitis as an adult, which was the only variable apart from age with significant negative impact on hearing in our data. This analysis was only completed for the 522 participants tested with the Interacoustics AD226 audiometer, thus excluding those who were tested with the audiometer with $+10 \mathrm{~dB}$ as the minimum test level. In a separate linear regression analysis, we excluded participants with prior otitis as an adult instead of adjusting for this. This analysis was completed for 453 participants tested with the Interacoustics AD226 audiometer.

Statistical significance was set at $p<0.05$. The data were analyzed using IBM SPSS Statistics, version 21.

\section{Research ethics}

The study was performed in accordance with the 1964 Declaration of Helsinki and its later amendments. The study protocol was approved by the Regional Committees for Medical and Health Research Ethics, REC South East. The participants were informed about the objectives and conditions of the study and gave their informed consent. The participants received no payment for participating in the study, and they could withdraw from the study at any point. Individual data from the study could not be used as a basis for medical selection of candidates. The Royal Norwegian Navy permitted all available results on group level to be published. 


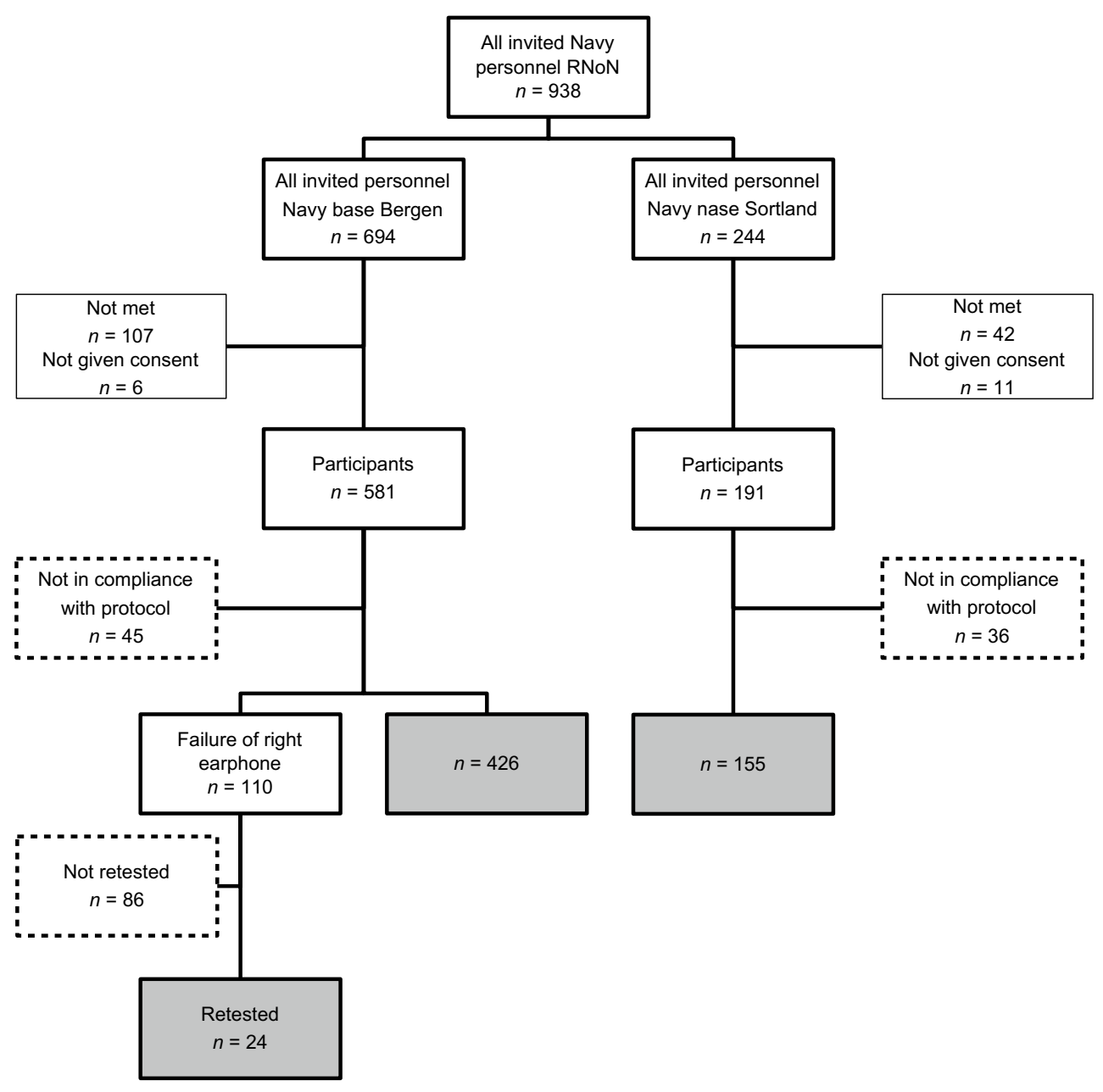

Fig. 1 Flowchart describing a study among Navy personnel in Norway, 2012-2013. Gray boxes indicate participants included in the analysis $(n=605)$. Dotted lines indicate participants excluded from the analysis $(n=167)$

\section{Results}

The study population consisted of 605 participants, of which 569 were male and 36 female. The mean age of the participants was 30 years, with a range from 19 to 62 years. A total of 190 participants $(31.4 \%)$ had hearing loss defined as hearing threshold levels $\geq 25 \mathrm{~dB}$ in either ear at $3,000,4,000$ or $6,000 \mathrm{~Hz}$.

The prevalence of hearing loss was significantly higher among navigators $(37.0 \%)$ and engine room personnel $(38.0 \%)$ than electricians $(23.6 \%)$ (Table 2$)$.

The log binomial regression $(n=605)$ showed that hearing loss was significantly associated with age, the work exposure variables: years of work in the Navy, years on vessel(s) in the Navy and years of sailing in the Navy, otitis as an adult, attending concerts/disco and use of Mp3 player (Table 3).

The prevalence of hearing loss was $50.3 \%$ among Navy personnel aged above 33 years, and $23.0 \%$ among those aged below 24 years (Table 3). Navy personnel who had sailed for more than three years in the Navy had a $46.4 \%$ prevalence of hearing loss, while the prevalence was $26.4 \%$ among the Navy personnel who had sailed in the Navy for less than one year (Table 3). However, the work exposure variables were all significantly intercorrelated (Pearson correlation) with age: years of work in the Navy ( $\mathrm{R}=0.88, p<0.001$ ), years on vessel(s) in the Navy $(\mathrm{R}=0.85, p<0.001)$ and years of sailing in the Navy $(\mathrm{R}=0.80, p<0.001)$. Among the 77 participants who had experienced otitis as an adult, $50.6 \%$ had hearing loss (Table 3). Two determinants were associated with a reduced risk of hearing loss: attending concerts/disco and using Mp3 player (Table 3). No association was observed between hearing loss and the following variables from the questionnaire: impulse noise, use of hearing protection, work with organic solvents, diving, heart disease, hypertension, diabetes, otitis as a child, reduced hearing in closest family, episodes of temporary reduced hearing, admittance 
Table 2 Prevalence and relative risk (RR) of hearing loss by job category in a study of 605 Navy personnel in Norway, 2012-2013

\begin{tabular}{|c|c|c|c|c|c|}
\hline Job category & $\begin{array}{l}\text { Total number }{ }^{\mathrm{a}} \\
n\end{array}$ & Mean age $(\min -\max )$ & $\begin{array}{l}\text { Hearing loss }{ }^{\mathrm{b}} \\
n(\%)\end{array}$ & RR & $95 \% \mathrm{CI}$ \\
\hline Electrician & 106 & $28(20-48)$ & $25(23.6)$ & 1 (ref) & \\
\hline Work on deck & 88 & $26(19-46)$ & $22(25.0)$ & 1.06 & $0.64-1.75$ \\
\hline Work in ships office & 36 & $29(20-47)$ & $10(27.8)$ & 1.18 & $0.63-2.21$ \\
\hline Cook & 25 & $26(19-53)$ & $8(32.0)$ & 1.36 & $0.70-2.64$ \\
\hline Work in operation room & 118 & $29(19-50)$ & $40(33.9)$ & 1.44 & $0.94-2.20$ \\
\hline Navigator & 119 & $34(23-62)$ & $44(37.0)$ & $1.57 *$ & $1.04-2.38$ \\
\hline Engine room personnel & 108 & $31(19-54)$ & $41(38.0)$ & $1.61 *$ & $1.06-2.45$ \\
\hline
\end{tabular}

Log binomial analysis

* Statistical significance

a Job category was missing for five participants

${ }^{b}$ Hearing loss defined as $\geq 25 \mathrm{~dB}$ in either ear at $3,000,4,000$ or $6,000 \mathrm{~Hz}$

to hospital due to head injury, ototoxic medication, use of cigarettes, use of moist snuff, hunting and number of gunshots the previous year or playing in a band (data not shown).

Using the age and gender-adjusted variable $\Delta$ Hearing threshold and adjusting for otitis as an adult in a linear regression model $(n=522)$, the hearing threshold level increased significantly for all the three work exposure variables at 1,000 and $4,000 \mathrm{~Hz}$ (Table 4). The hearing threshold level at 3,000 Hz was significantly increased only for the work exposure variable years of sailing in the Navy. Among the three work exposure variables, years of sailing in the Navy was the strongest predictor of impaired hearing. There was no statistically significant association between the work exposure variables and hearing threshold levels at $6,000 \mathrm{~Hz}$ (a frequency often associated with NIHL), nor at the frequencies $250,500,2,000$ or $8,000 \mathrm{~Hz}$. In the separate analysis in which participants with prior otitis as an adult were excluded $(n=69)$, the hearing threshold level was significantly increased for the work exposure variable years of sailing in the Navy at 1,000, 3,000 and $4,000 \mathrm{~Hz}$ (data not shown). Years on vessel(s) in the Navy was associated with a significantly poorer hearing threshold at 4,000 Hz. Years of work in the Navy was not associated with impaired hearing thresholds in this analysis.

\section{Discussion}

The prevalence of hearing loss among Navy personnel was $31.4 \%$. Hearing loss was associated with the work exposure variables: years of work in the Navy, years on vessel(s) in the Navy and years of sailing in the Navy, as well as age and otitis as an adult. When adjusting for age, gender and otitis as an adult, higher hearing thresholds at 1,000 and 4,000 $\mathrm{Hz}$ were found when assessing the work exposure variables. Of the three work exposure variables, years of sailing in the Navy was the strongest predictor of hearing loss in our study and suggests that work on board $\mathrm{RNoN}$ vessels is detrimental to hearing.

Similar results were also found when excluding participants with prior otitis as an adult. However, for years of employment and years on vessel(s) in the Navy, this association was weaker and might be explained by the smaller sample size when excluding those with prior otitis as an adult. Using Mp3 player and attending concerts/ disco seemed to have a positive impact on hearing. This finding might be related to the assumption that those who listen to loud music may tolerate the noise exposure, hence not developing hearing loss. Another explanation can be that those who already have developed hearing loss give up attending concerts/disco and listening to Mp3 player in order to avoid further deterioration of hearing. However, usage of Mp3 player and attending concerts was inversely associated with age and years of employment and the observed association may therefore have been confounded. The prevalence of hearing loss was significantly higher among navigators and engine room personnel than among electricians, suggesting that the noise exposure varies with job category.

Hearing loss can be classified in numerous ways, rendering comparison of hearing loss between different studies a challenge (Rabinowitz et al. 2012). Frequencies most important for speech discrimination can be emphasized (e.g., the U.S. Navy), while our definition is based on frequencies associated with NIHL. The U.S. Navy uses "significant threshold shift" (STS), which is defined as a change in hearing threshold relative to the initial reference audiogram of $10 \mathrm{~dB}$ or more averaged over 2,000, 3,000, and 4,000 Hz, in either ear (DoDI 6055.12 2013).

As an example, a U.S. study has stated that the STS prevalence would be higher if using the criteria set by the 
Table 3 Significant determinants with effect on hearing, measured in 605

Navy personnel in Norway, 2012-2013

\begin{tabular}{|c|c|c|c|c|c|}
\hline Determinant & & $\begin{array}{l}\text { Hearing loss } \\
n(\%)\end{array}$ & $\begin{array}{l}\text { Normal hearing } \\
n(\%)\end{array}$ & RR & $95 \% \mathrm{CI}$ \\
\hline \multirow[t]{4}{*}{$\mathrm{Age}^{\mathrm{b}}$} & $<24$ years (ref) & $42(23.0)$ & $141(77.0)$ & 1 & \\
\hline & 24-27 years & $29(25.0)$ & $87(75.0)$ & 1.09 & $0.72-1.65$ \\
\hline & 28-33 years & $39(26.5)$ & $108(73.5)$ & 1.16 & $0.79-1.69$ \\
\hline & $>33$ years & $80(50.3)$ & $79(49.7)$ & $2.19 *$ & $1.61-2.98$ \\
\hline \multirow[t]{4}{*}{ Years of work in the Navy ${ }^{b}$} & $0-2$ years (ref) & $30(21.9)$ & $107(78.1)$ & 1 & \\
\hline & $2.1-5$ years & $39(26.2)$ & $110(73.8)$ & 1.20 & $0.79-1.81$ \\
\hline & $5.1-11$ years & $42(26.9)$ & $114(73.1)$ & 1.23 & $0.82-1.85$ \\
\hline & $>11$ years & $78(48.4)$ & $83(51.6)$ & $2.21 *$ & $1.55-3.15$ \\
\hline \multirow[t]{4}{*}{ Years on vessel(s) in the Navy ${ }^{b}$} & $0-2$ years (ref) & $49(24.1)$ & $154(75.9)$ & 1 & \\
\hline & $2.1-4$ years & $35(29.7)$ & $83(70.3)$ & 1.23 & $0.85-1.78$ \\
\hline & 4.1-9 years & $32(22.2)$ & $112(77.8)$ & 0.92 & $0.62-1.36$ \\
\hline & $>9$ years & $73(52.9)$ & $65(47.1)$ & $2.19 *$ & $1.64-2.93$ \\
\hline \multirow[t]{3}{*}{ Years of sailing in the Navy ${ }^{b}$} & $<1$ year $($ ref $)$ & $73(26.4)$ & $203(73.6)$ & 1 & \\
\hline & $1.1-3$ years & $28(21.7)$ & $101(78.3)$ & 0.82 & $0.56-1.20$ \\
\hline & $>3$ years & 85 (46.4) & $98(53.6)$ & $1.76^{*}$ & $1.37-2.26$ \\
\hline \multirow[t]{3}{*}{ Otitis as an adult } & No (ref) & $139(29.1)$ & $338(70.9)$ & 1 & \\
\hline & Yes & $39(50.6)$ & $38(49.4)$ & $1.74 *$ & $1.34-2.26$ \\
\hline & I don't know & $12(24.0)$ & $38(76.0)$ & 0.82 & $0.49-1.38$ \\
\hline \multirow[t]{3}{*}{ Concerts/disco } & Seldom/never (ref) & $57(45.6)$ & $68(54.4)$ & 1 & \\
\hline & Sometimes/year & $76(29.8)$ & $179(70.2)$ & $0.65^{*}$ & $0.50-0.86$ \\
\hline & $\geq$ Sometimes/month & $57(25.6)$ & $166(74.4)$ & $0.56^{*}$ & $0.42-0.75$ \\
\hline \multirow[t]{3}{*}{ Mp3 player } & Seldom/never (ref) & $95(38.3)$ & $153(61.7)$ & 1 & \\
\hline & $1-2 \mathrm{~h} /$ week & $49(26.3)$ & 137 (73.7) & $0.69 *$ & $0.52-0.92$ \\
\hline & $\geq 3 \mathrm{~h} /$ week & $46(27.1)$ & $124(72.9)$ & $0.71 *$ & $0.53-0.95$ \\
\hline
\end{tabular}

Table 4 Age and gender-adjusted (ISO 7029) $\Delta$ Hearing threshold related to years of noise exposure among 522 Navy personnel in Norway, 2012-2013

\begin{tabular}{|c|c|c|c|c|c|c|c|c|}
\hline \multirow[t]{3}{*}{ Work exposure } & \multicolumn{8}{|c|}{ Audiometry frequency $(\mathrm{Hz})$} \\
\hline & \multicolumn{2}{|l|}{1,000} & \multicolumn{2}{|l|}{3,000} & \multicolumn{2}{|l|}{4,000} & \multicolumn{2}{|l|}{6,000} \\
\hline & $\beta$ & $95 \% \mathrm{CI}$ & $\beta$ & $95 \% \mathrm{CI}$ & $\beta$ & $95 \% \mathrm{CI}$ & $\beta$ & $95 \% \mathrm{CI}$ \\
\hline Years of work in the Navy & $0.11 *$ & $0.02,0.21$ & 0.05 & $-0.05,0.16$ & $0.15^{*}$ & $0.03,0.28$ & -0.04 & $-0.20,0.12$ \\
\hline Years on vessel(s) in the Navy & $0.19 *$ & $0.07,0.31$ & 0.10 & $-0.04,0.23$ & $0.24 *$ & $0.07,0.40$ & -0.07 & $-0.28,0.15$ \\
\hline Years of sailing in the Navy & $0.35^{*}$ & $0.17,0.54$ & $0.26 *$ & $0.05,0.47$ & $0.48 *$ & $0.22,0.73$ & -0.12 & $-0.45,0.21$ \\
\hline
\end{tabular}

Adjusted for otitis as an adult

Linear regression analysis with $\beta$ in $\mathrm{dB} / \mathrm{year}$

* Statistical significance

Occupational Safety and Health Administration (OSHA) rather than using those set by the U.S. Navy (Wolgemuth et al. 1995).

The prevalence of hearing loss in the present study was $31.4 \%$. In a previous study, self-reported hearing loss was prevalent among $24 \%$ of RNoN personnel (Moen et al. 2008). In contrast only $3 \%$ of the population in a national population health survey reported hearing loss (Norway 2003) and the prevalence of disabling hearing loss among inhabitants in a Norwegian county was $10.3 \%$ (Engdahl and Tambs 2010). In studies based on data from the U.S. Navy Hearing Conservation Program, the rate of total STS varied between $18.1 \%$ (Bohnker et al. 2002b) and $29 \%$ (Wolgemuth et al. 1995). The higher prevalence of hearing loss in our study suggests that the hearing loss can be attributed to work on board RNoN vessels.

We found an association between reduced hearing and work on board navy vessels. In a study comparing hearing 
thresholds in U.S. Navy and Marine Corps with OSHA age-corrected values of hearing thresholds (Bohnker et al. 2002a), it was concluded that men in Navy and Marine Corps had higher threshold levels than according to OSHA. Another study reported that working on board surface warships was more damaging to hearing than work at shore duty stations (Trost and Shaw 2007), and an increased risk of hearing impairment was indicated in a study among flight deck personnel and engine room workers on an aircraft carrier compared with administrative personnel (Rovig et al. 2004). The relationship between noise exposure on board Navy vessels and reduced hearing seen in prior studies is in line with our findings.

In the present study, we found an association between noise exposure and higher hearing thresholds at 1,000$4,000 \mathrm{~Hz}$ but not at $6,000 \mathrm{~Hz}$. It has been reported that hearing loss appears differently depending on whether the noise exposure is continuous or results from impulse noise, like explosions and firing cannons. Continuous noise exposure tends to result in notching at $4,000 \mathrm{~Hz}$ (McBride and Williams 2001). Two studies which described exposure to acoustic trauma among Finnish conscripts and Finnish surviving suicide bomb victims both found the poorest hearing thresholds at $6,000 \mathrm{~Hz}$ (Mrena et al. 2004; Ylikoski 1989). However, this is only partly in line with findings from the larger Norwegian study, which observed approximately equal hearing thresholds at 3,000, 4,000, 6,000, and $8,000 \mathrm{~Hz}$ among men exposed to impulse noise (Tambs et al. 2006). Thus, based on prior literature, it is difficult to conclude whether the reduced hearing found in our study is caused by the continuous noise exposure on board or by impulse noise.

The highest prevalence of hearing loss was seen among engine room personnel (38.0\%). Comprehensive noise level measurements on board Navy vessels have barely been reported; however, studies from commercial vessels have shown that noise levels in engine rooms range from around 90 to $110 \mathrm{~dB}(\mathrm{~A})$ (Neitzel et al. 2006; Svendsen and Børresen 1999; Turan et al. 2011). In a study among Danish seafarers and fishermen, the engine room personnel had a 2.39 times greater risk of hearing loss compared with other seafarers (Kaerlev et al. 2008). In U.S Navy studies the prevalence of STS among enginemen varies between 18.0 and $20.2 \%$ (Bohnker et al. 2002b; Wolgemuth et al. 1995). The high prevalence of hearing loss among engine room personnel seen in our study might be due to high noise levels in engine rooms on board RNoN vessels.

The lowest prevalence of hearing loss in our study was seen among electricians $(23.6 \%)$. Noise levels in the engine control room (where electricians have their work site) of ferries, cargo ships and westamarans range from around 70 to $90 \mathrm{~dB}(\mathrm{~A})$ (Svendsen and Børresen 1999). These levels are lower than the levels in the engine rooms
(Neitzel et al. 2006; Svendsen and Børresen 1999; Turan et al. 2011), but may still represent a hazard to hearing for sensitive individuals. Previous studies have also shown that electricians have a low prevalence of hearing loss, even lower than in our study. A U.S. Navy study comparing rates of STS found the lowest value among "Electronics technicians" (5.0\%) (Wolgemuth et al. 1995). Another U.S. Navy study which compared rates of STS among Navy and Marine Corps found STS prevalence ranging from 15.8 to $23.8 \%$ among electrician groups (Bohnker et al. 2002b). The somewhat higher prevalence of hearing loss among electricians in our study might be due to higher noise levels in engine control rooms on board RNoN vessels than in the previously studied vessels.

The response rate in this study was high (81.4\%); however, the participation rate was only $63.8 \%$. This was due to the fact that data were collected in accordance with a stringent protocol. There is no reason to believe that the excluded participants differ from the ones included. We have limited information about the 149 who did not meet for examination and the 17 who did not give consent to participate; hence, we cannot rule out that these non-responders differed from the responders.

Few previous studies on hearing loss among Navy personnel have provided information on confounding factors that might be responsible for hearing loss (Henselman et al. 1995). In our study, a questionnaire regarding occupational and non-occupational noise exposure and other possible determinants of hearing loss was used, which made it possible to adjust for non-occupational determinants in the analysis.

All invited personnel were informed that individual data would not be used to assess medical skillfulness, with criteria for hearing thresholds that must be fulfilled in order to be allowed work on board. Furthermore, there is no reason to believe that recorded hearing thresholds have been biased by participants striving to get a result adequate to be allowed to work on board.

We chose to use ISO 7029 (2000) as a reference to hearing thresholds in the general population. One alternative could be to age adjust in the log binomial analysis, but this would introduce an over-adjustment, as age and years of noise exposure are closely correlated. Hearing loss is present in the youngest age-group ( $<24$ years), suggesting that hearing loss in this population is probably primarily caused by noise exposure and less by aging. The ISO 7029 consists of a screened population free of all symptoms of ear disease, without obstructing wax and without undue history of noise exposure, hence similar to our population with the sole exception of noise exposure (ISO 7029 2000). We chose to calculate the expected hearing thresholds using the 50 percentile, although one could defend choosing 75 or 90 percentiles (acquiring lower hearing 
thresholds), as our population was screened before enrollment, and one would expect a better hearing than for the population in general. However, choosing these percentiles would make the difference between estimated and measured hearing thresholds even greater, strengthening the results of our study. An alternative to choosing ISO 7029 as a reference was ISO 1999, data base B (ISO 1999 2013), which is based on a Norwegian population and presents hearing threshold levels as a function of age of an unscreened population. However, as personnel are screened when enrolled in the Navy, we chose to compare with the screened population of ISO 7029 instead. As we wished to adjust hearing thresholds at an individual rather than on a group level, we found that ISO 7029 was the preferable reference material.

Although we found coherence between years of sailing in the Navy and impaired hearing, the cross-sectional study design cannot clarify cause and effect.

In the RNoN today, no definite protocol is established on how to follow up personnel with recognized hearing loss. We hope that this study, stating a high prevalence of hearing loss, will contribute to further awareness of the noise problem on board. Noise measurements and subsequent protection against high noise levels should be implemented, and a hearing conservation program should be established in order to improve working conditions on board. As the population is young, the benefit from prevention is great and hearing can still be protected and preserved.

Acknowledgments We thank Ellen Skare, Unni Nicolaysen, Pål Pedersen and Jane Berit Berg for collecting the data; Hjalmar Johansen, Christin Pedersen and Eirik Veum Vilhelmsen for being contact persons in the Navy; Ågot Irgens for helpful support with the statistics; Truls Gjestland, Ole Jacob Møllerløkken, Hilde Gundersen, Camilla Hauge, Gunhild Koldal and Lorentz Irgens for valuable contributions in the writing process. The study is funded by the Royal Norwegian Navy.

Conflict of interest The authors declare that they have no conflict of interest.

Open Access This article is distributed under the terms of the Creative Commons Attribution License which permits any use, distribution, and reproduction in any medium, provided the original author(s) and the source are credited.

\section{References}

Bohnker BK, Page JC, Rovig G, Betts LS, Muller JG, Sack DM (2002a) U.S. Navy and Marine Corps Hearing Conservation Program, 1995-1999: mean hearing thresholds for enlisted personnel by gender and age groups. Mil Med 167:132-135

Bohnker BK, Page JC, Rovig G, Betts LS, Sack DM (2002b) Navy hearing conservation program: threshold shifts in enlisted personnel, 1995-1999. Mil Med 167:48-52

DoDI 6055.12 Department of defence instruction 6055.12
Engdahl B, Tambs K (2010) Occupation and the risk of hearing impairment—results from the Nord-Trøndelag study on hearing loss. Scand J Work Environ Health 36:250-257

Henselman LW, Henderson D, Shadoan J, Subramaniam M, Saunders S, Ohlin D (1995) Effects of noise exposure, race, and years of service on hearing in U.S. Army soldiers. Ear Hear 16:382-391

Irgens-Hansen K, Moen BE, Bråtveit M, Hauge C, Sunde E (2013) Noise exposure and hearing loss among naval personnel. Occup Environ Med 70:A36

ISO 1999 (2013) Acoustics-Estimation of noise-induced hearing loss

ISO 7029 (2000) Acoustics - Statistical distribution of hearing thresholds as a function of age. International Organization for Standardization, Geneva

ISO 8253-1 (2010) Acoustics-Audiometric test methods-Part 1: pure-tone air and bone conduction audiometry. International Organization for Standardization, Geneva

Kaerlev L, Jensen A, Nielsen PS, Olsen J, Hannerz H, Tuchsen F (2008) Hospital contacts for noise-related hearing loss among Danish seafarers and fishermen: a population-based cohort study. Noise Health 10:41-45

Koefoed V (2011) Skipsstøy og helseeffekter. Ramazzini 18:11-13 (in Norwegian)

McBride DI, Williams S (2001) Audiometric notch as a sign of noise induced hearing loss. Occup Environ Med 58:46-51

Moen BE, Koefoed VF, Bondevik K, Haukenes I (2008) A survey of occupational health in the royal Norvegian navy. Internat Marit Health 59:35-44

Mrena R, Paakkonen R, Back L, Pirvola U, Ylikoski J (2004) Otologic consequences of blast exposure: a finnish case study of a shopping mall bomb explosion. Acta Oto-laryngol 124:946-952

Neitzel R, Berna B, Seixas N (2006) Noise exposure aboard catcher/ processor fishing vessels. Am J Ind Med 49:624-633

Nelson DI, Nelson RY, Concha-Barrientos M, Fingerhut M (2005) The global burden of occupational noise-induced hearing loss. Am J Ind Med 48:446-458

Norway S (2003) Statistisk årbok 2003 Levekårsundersøkelsen om helse, omsorg og sosial kontakt (A study on health, welfare and social contact, in Norway) (In Norwegian)

Rabinowitz PM, Galusha D, McTague MF, Slade MD, Wesdock JC, Dixon-Ernst C (2012) Tracking occupational hearing loss across global industries: a comparative analysis of metrics. Noise Health 14:21-27

Rovig GW, Bohnker BK, Page JC (2004) Hearing health risk in a population of aircraft carrier flight deck personnel. Mil Med 169:429-432

Svendsen K, Børresen E (1999) Measurements of mineral oil mist, hydrocarbon vapor, and noise in engine rooms of ships. Appl Occup Environ Hyg 14:186-191

Tambs K, Hoffman HJ, Borchgrevink HM, Holmen J, Engdahl B (2006) Hearing loss induced by occupational and impulse noise: results on threshold shifts by frequencies, age and gender from the Nord-Trøndelag Hearing Loss Study. Int J Audiol 45(5):309-317

Trost RP, Shaw GB (2007) Statistical analysis of hearing loss among navy personnel. Mil Med 172:426-430

Turan O, Helvacioglu IH, Insel M, Khalid H, Kurt RE (2011) Crew noise exposure on board ships and comparative study of applicable standards. Ships Offshore Struct 6:323-338

Wolgemuth KS, Luttrell WE, Kamhi AG, Wark DJ (1995) The effectiveness of the navy's hearing conservation program. Mil Med 160:219-222

Ylikoski J (1989) Acute acoustic trauma in finnish conscripts. Etiological factors and characteristics of hearing impairment. Scand Audiol 18:161-165 